\title{
Antimicrobial Microwebs of DNA-Histone Inspired from Neutrophil Extracellular Traps
}

\author{
Yang Song, Usha Kadiyala, Priyan Weerappuli, Jordan J. Valdez, Srilakshmi Yalavarthi, \\ Cameron Louttit, Jason S. Knight, James J. Moon, David S. Weiss, J. Scott VanEpps, ** \\ and Shuichi Takayama*
}

Neutrophil extracellular traps (NETs) are decondensed chromatin networks released by neutrophils that can trap and kill pathogens but can also paradoxically promote biofilms. The mechanism of NET functions remains ambiguous, at least in part, due to their complex and variable compositions. To unravel the antimicrobial performance of NETs, a minimalistic NET-like synthetic structure, termed "microwebs," is produced by the sonochemical complexation of DNA and histone. The prepared microwebs have structural similarity to NETs at the nanometer to micrometer dimensions but with welldefined molecular compositions. Microwebs prepared with different DNA to histone ratios show that microwebs trap pathogenic Escherichia coli in a manner similar to NETs when the zeta potential of the microwebs is positive. The DNA nanofiber networks and the bactericidal histone constituting the microwebs inhibit the growth of $E$. coli. Moreover, microwebs work synergistically with colistin sulfate, a common and a last-resort antibiotic, by targeting the cell envelope of pathogenic bacteria. The synthesis of microwebs enables mechanistic studies not possible with NETs, and it opens new possibilities for constructing biomimetic bacterial microenvironments to better understand and predict physiological pathogen responses. with antimicrobial protein granules and enzymes. ${ }^{[5]}$ NETs have been observed to be lethal to a number of bacteria, ${ }^{[6]}$ fungi, ${ }^{[7]}$ viruses, ${ }^{[8]}$ and parasites, ${ }^{[9]}$ yet some pathogenic bacteria can evade NET-induced killing. ${ }^{[10,11]}$ Accumulation of excessive NETs in vivo is also associated with pathology of bacterial biofilm, autoimmune disease, and even cancer. ${ }^{[12]}$ These complex and sometimes contradictory observations highlight the need to investigate NET-related physiological interactions with simpler but defined NET-like biomaterials.

Isolation of NETs from neutrophils requires repeated centrifugation and washing steps, ${ }^{[13]}$ which often causes unpredictable loss of proteins. Moreover, NETs can be triggered via chemical stimulus, ${ }^{[14]}$ virulence factors, ${ }^{[15]}$ and bacteria ${ }^{[16]}$ under different pathways, yielding 33 common proteins and as much as 50 variable proteins. ${ }^{[12]}$ While the existing antibodies and inhibitors are employed to block and
Nature uses a variety of extracellular nanofibers, such as cobwebs, ${ }^{[1]}$ amyloid plaques, ${ }^{[2]}$ and fibrin clots $^{[3]}$ to capture invading microbes. As part of human innate immunity, neutrophils squirt decondensed chromatin networks to capture and disarm bacteria and fungi-a host defense process known as "NETosis"[4] (Figure 1a). Such endogenous networks, named neutrophil extracellular traps (NETs; Figure 1b), are composed of meshes of DNA strands and histone, decorated

Dr. Y. Song, Prof. S. Takayama

Wallace H Coulter Department of Biomedical Engineering \& Petit

Institute for Bioengineering and Bioscience

Georgia Institute of Technology \& Emory School of Medicine

Atlanta, GA 30332, USA

E-mail: takayama@gatech.edu

U. Kadiyala, Dr. J. S. VanEpps

Department of Emergency Medicine

Michigan Center for Integrative Research in Critical Care

Biointerfaces Institute

University of Michigan

Ann Arbor, MI 48109, USA

E-mail: jvane@med.umich.edu

The ORCID identification number(s) for the author(s) of this article can be found under https://doi.org/10.1002/adma.201807436. characterize the function of specific NET components, their high complexity imposes limitations. ${ }^{[17]}$ Here, we take a bottom-up approach of synthesizing NET-like materials with defined composition, termed "microwebs," through sonochemical complexation of lambda phage DNA and histone in aqueous solutions. Lambda phage DNA can spontaneously polymerize into networks in the presence of histone, ${ }^{[18]}$ which facilitates formation of web-like structure. Escherichia coli UTI89 was used as a model pathogen
DOI: 10.1002/adma.201807436
P. Weerappuli, C. Louttit, Dr. J. J. Moon

Department of Biomedical Engineering

University of Michigan

Ann Arbor, MI 48109, USA

. I. Valdez, Dr. D. S. Weis

Emory Vaccine Cente

School of Medicine

Emory University

Atlanta, GA 30307, USA

Dr. S. Yalavarthi, Dr. I. S. Knight

Division of Rheumatology

University of Michigan

Ann Arbor, MI 48109, USA
Emory Antibiotic Resistance Center 
(a)

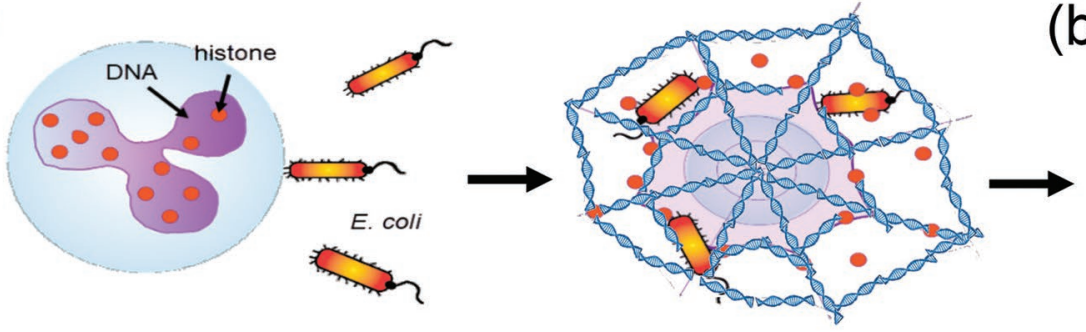

NETosis: cellular generation of chromatin network to capture and kill microbes (b)

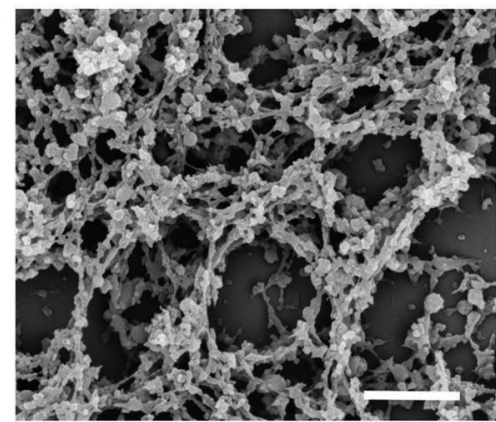

(c)

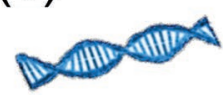

DNA

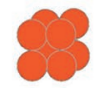

histone
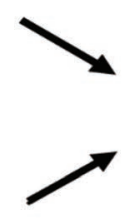

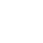

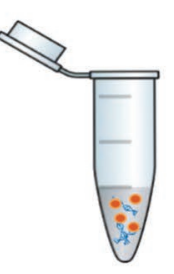

Microwebs: artificial NET-like DNA/histone with antimicrobial functions
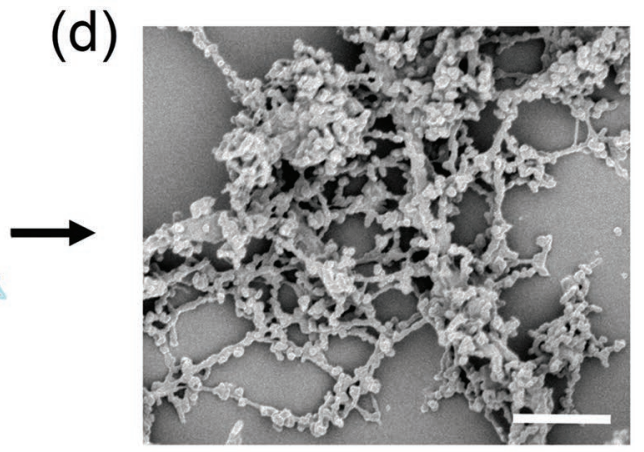

(e)

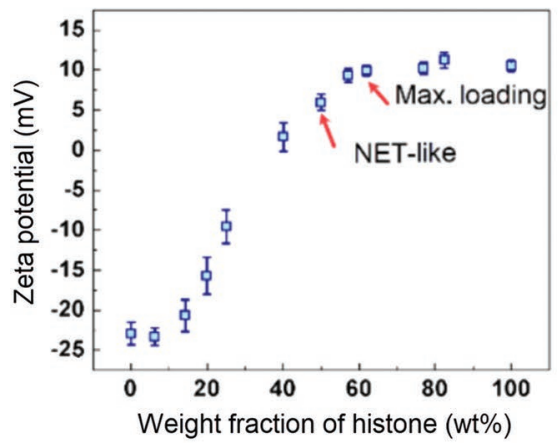

(f)

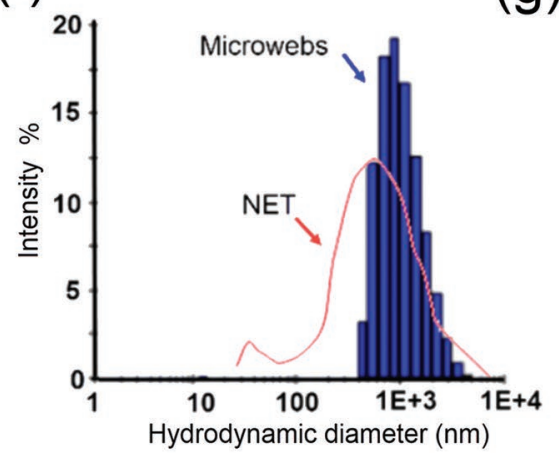

(g)

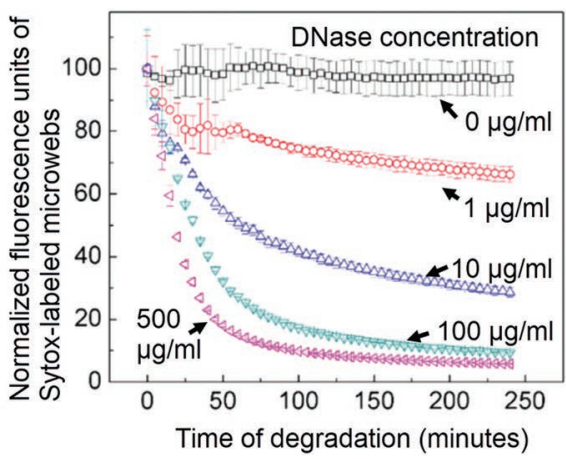

Figure 1. Synthesis and characterization of NET-like microwebs. a) Scheme and b) scanning electron microscopy illustrating NETs. c) Scheme and d) SEM illustrating microwebs. Scale bars $=1 \mu \mathrm{m}$. e) Zeta potentials and f) size distribution (DLS measurement) of microwebs. Size distribution of sonicated NETs is shown by the red curve. g) DNase-induced degradation of microwebs in HBSS. Microwebs were stained by SYTOX $(E x / E m=488 / 523 \mathrm{~nm})$.

because NETs were essential for the clearance of E. coli; moreover, the first clinical isolate of colistin-resistant bacteria harboring the mcr-1 gene in the US was E. coli from a urinary tract infection (UTI) ${ }^{[19]}$ We evaluated the antimicrobial performance of NETs versus microwebs of different composition in comparative studies. We show how the microwebs trap E. coli and inhibit their growth as NETs do. In addition, we demonstrate that the microwebs can work synergistically with colistin sulfate to kill E. coli. Compared to isolation of NETs from neutrophils, our synthetic approach allows fast and larger-scale preparation of NET-like structures with well-defined compositions. This approach therefore provides a platform to study mechanisms of NET-bacteria interactions with less confounding factors to promote understanding of NET-related human diseases.

Inspired from decondensed chromatin structure of NETs, our synthetic "microwebs" were prepared by a sonicated mixture solution of DNA and histone (see the Experimental Section). Methylated lambda phage DNA was selected to formulate microwebs because its DNA length (48502 bp) is suitable for forming uniform and dispersible networks by sonication. At physiological DNA concentrations $\left(\approx 100 \mu \mathrm{g} \mathrm{mL} \mathrm{m}^{-1}\right)$, shorter DNA only forms microparticles with histone in Hank's balanced salt solution (HBSS), while longer DNA results in large clumps that cannot be easily dispersed. After applying ultrasonication to the phage DNA/histone mixture, we obtained disassembled DNA-rich bundles decorated with histone-rich granules (Figure 1c,d). The resultant structure showed qualitative ultrastructural similarity to NETs collected from neutrophils. The thickness of the DNA bundles varied from 20 to $100 \mathrm{~nm}$, in agreement with ultrafine nanostructures observed in NETs. ${ }^{[20]}$ The formation of the microwebs is driven by the electrostatic complexation of DNA (zeta potential, $\zeta=-22 \mathrm{mV}$ ) with 
histone $(\zeta=+11.3 \mathrm{mV})$. When the histone weight fraction in the microwebs, $\omega_{\text {his }}$, was increased from 15 to $60 \mathrm{wt} \%$, the DNA fibers were gradually covered by a coating of histone granules (Figure S1, Supporting Information), resulting in elevated zeta potentials (Figure 1e). When the histone fraction $\omega_{\text {his }}$ is above an upper limit of $60 \mathrm{wt} \%$, the DNA-rich bundles were fully occupied by histone granules and therefore further attachment of histone to DNA was inhibited by electrostatic repulsion.

The maximum protein-loading capacity of the microwebs, $\omega_{\text {his,max }}=60 \mathrm{wt} \%$, is consistent with the reported fraction of all proteins in NETs (including histone, neutrophil elastase, cathepsin G, and other proteins) measured by mass spectrometry. ${ }^{[13]}$ Microwebs with $\omega_{\text {his }}=50 \mathrm{wt} \%$ acquire ultrafine structures like NETs. Dynamic light scattering (DLS) measurement of the sonicated microwebs suggests that the hydrodynamic diameter of the DNA bundles is comparable to that in NETs (Figure 1f). Due to the presence of histone, DNA colloids slowly aggregate and their hydrodynamic diameters increase over the time of aging (Figure S1, Supporting Information). Similar to NETs, the microwebs can be degraded by DNase I (Figure 1g). ${ }^{[6,21]}$ The degradation rate of microwebs increased with the DNase concentration, as shown by the fluorescence quenching of the SYTOX-labeled microwebs after degradation of DNA (Figure 1g; Figure S2, Supporting Information).

Since the primary function of NETs is to trap bacteria, ${ }^{[6]}$ we first tested the ability of microwebs to entrap the Gramnegative urinary pathogen, E. coli UTI89. Microwebs with different histone weight fractions, $\omega_{\text {his }}=25 \%, 40 \%, 50 \%$, and $57 \%$, were employed as matrices to trap bacteria. To enable sufficient contact between E. coli and microwebs, we sequentially centrifuged the microwebs and bacteria so that the planktonic $E$. coli cells were forced onto the precipitated microwebs at time zero, $t=0 \mathrm{~h}$. However, the temporarily attached E. coli can subsequently detach from the microwebs through bacterial movement. After $1 \mathrm{~h}$ of incubation, a near-steady-state bacterial entrapment was achieved, and the nonattached bacteria were removed by pipette washing. We observed that a higher density of E. coli cells was trapped on the positively charged microwebs than on the negatively charged and neutral microwebs, as shown by scanning electron microscopy (SEM) observation in Figure $2 \mathrm{a}-\mathrm{c}$. To quantify the number of entrapped bacteria, we prestained E. coli and then monitored the bacterial motion on microwebs for $1 \mathrm{~h}$ in HBSS. The entrapped E. coli cells were defined as those immobilized on microwebs without any observable motion, while the nonentrapped E. coli cells were

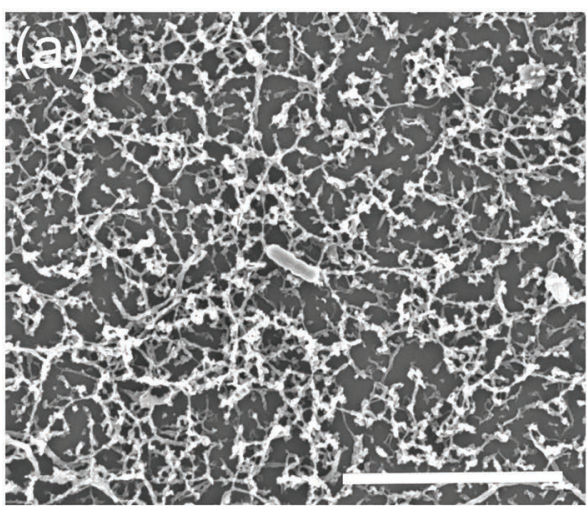

(d)

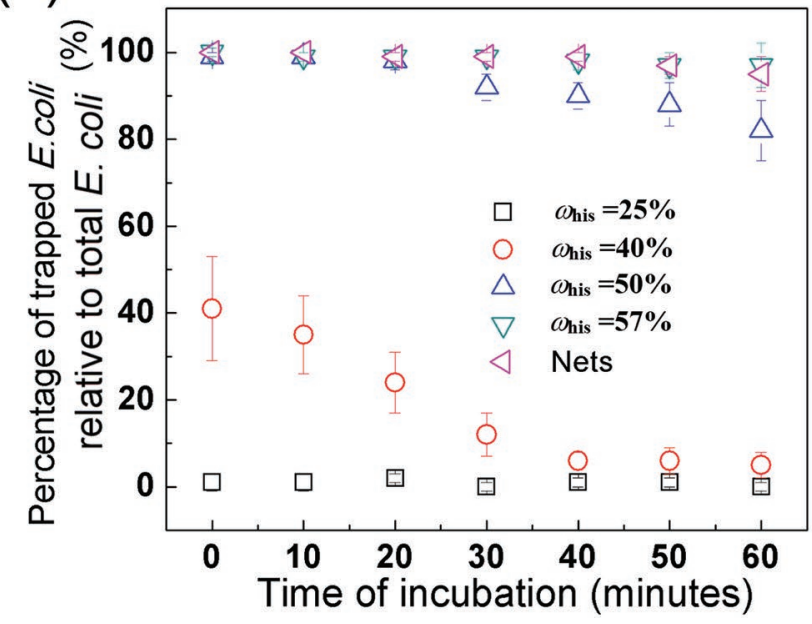

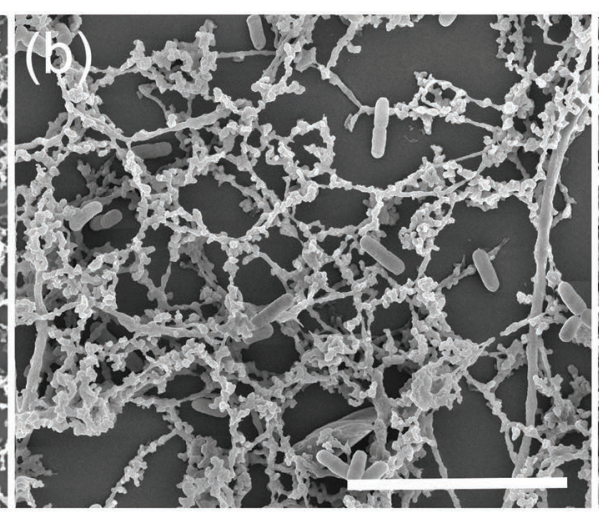

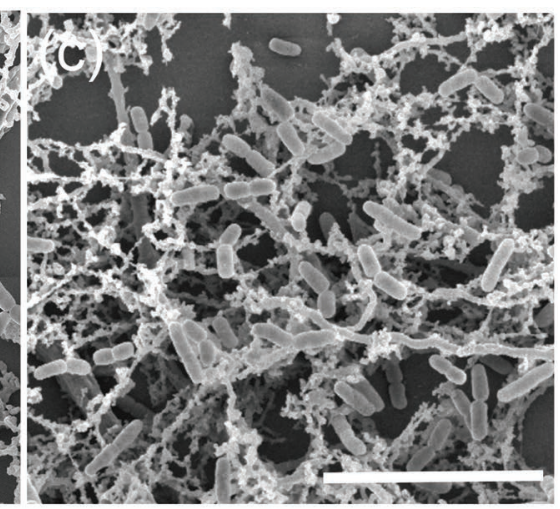

(e)

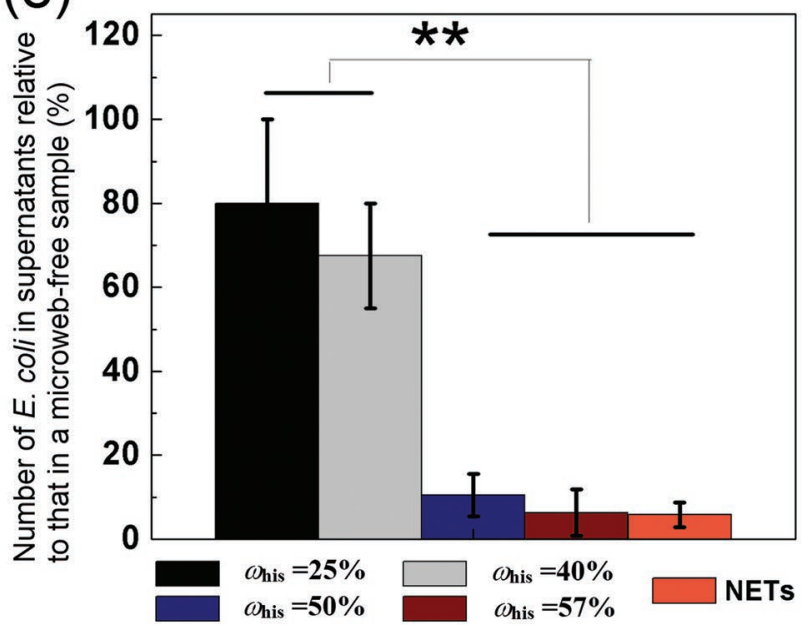

Figure 2. Entrapment of $E$. coli on microwebs. SEM images showing $E$. coli trapped on microwebs with a) $\zeta=-8 \mathrm{mV}, \mathrm{b}) \zeta=0 \mathrm{mV}$, and $\mathrm{c}) \zeta=+6.5 \mathrm{mV}$. Scale bars $=10 \mu \mathrm{m}$. d) The percentage of trapped E. coli on microwebs as a function of incubation time. e) The number of planktonic E. coli escaped from microwebs were counted by plating and colony forming unit enumeration. The percentage of planktonic E. coli is calculated from the ratio of E. coli in supernatants relative to that in NET-free control group. $* * P<0.01$. 
observed to self-rotate or swim to a different location under the microscope. After manually counting the number of motile and nonmotile $E$. coli, we found that $82 \% \pm 4 \%(\zeta=+5 \mathrm{mV}$, $\left.\omega_{\text {his }}=50 \%\right)$ and $93 \% \pm 3 \%\left(\zeta=+8 \mathrm{mV}, \omega_{\text {his }}=57 \%\right)$ E. coli cells were trapped on microwebs with positive zeta potentials, in good agreement with the trapping observed on NETs (Figure $2 \mathrm{~d}, \mathrm{e}){ }^{[22]}$ In contrast, less than $10 \%$ of $E$. coli cells were attached to the negatively charged $(-9 \mathrm{mV})$ and near-neutral $(-1$ to $+1 \mathrm{mV})$ microwebs. As the time of incubation increases, some E. coli cells initially attached to these microwebs were seen to detach. The membrane potential of these detached bacteria was elevated $(\zeta \approx 0 \mathrm{mV})$ compared to the untreated E. coli $(\zeta=-12 \mathrm{mV})$. This is probably caused by either adaption of bacteria to microwebs or adsorption of histone to the bacterial cell wall. The detached E. coli cells in supernatant was further enumerated by serial dilution, plating, and colony counting. The results confirmed that positively charged microwebs efficiently inhibited the dispersion of $E$. coli as compared to negatively charged microwebs (Figure 2e). The charge-dependent bacterial trapping can be explained by an energy barrier set by the electrostatic interaction between the bacterial cell wall (e.g., lipopolysaccharide) and microwebs. A higher fraction of cationic histone $\left(\omega_{\text {his }}>40 \%\right)$ in microwebs and therefore a higher electrostatic force enhanced the bacteria trapping efficiency.

To test if microwebs kill the trapped E. coli, we placed microwebs on top of $E$. coli cells through centrifugation and incubated the trapped E. coli for $1 \mathrm{~h}$ in HBSS. Subsequently, we removed the microwebs from $E$. coli cells by repeated washing and stained the remaining bacteria with the LIVE/DEAD BacLight bacterial viability kit. Using confocal laser scanning microscopy (CLSM), we found that most E. coli cells remained alive in microwebs and a small fraction were dead (red, Figure $3 b)$. SEM observation reveals that live bacteria had intact capsules similar to those cultured in tryptic soy broth (TSB) (Figure 3f). Some of the microweb-entrapped E. coli cells were seen to shrink similar to those trapped on NETs (Figure 3g,h). The successful permeation of propidium iodide into these cells
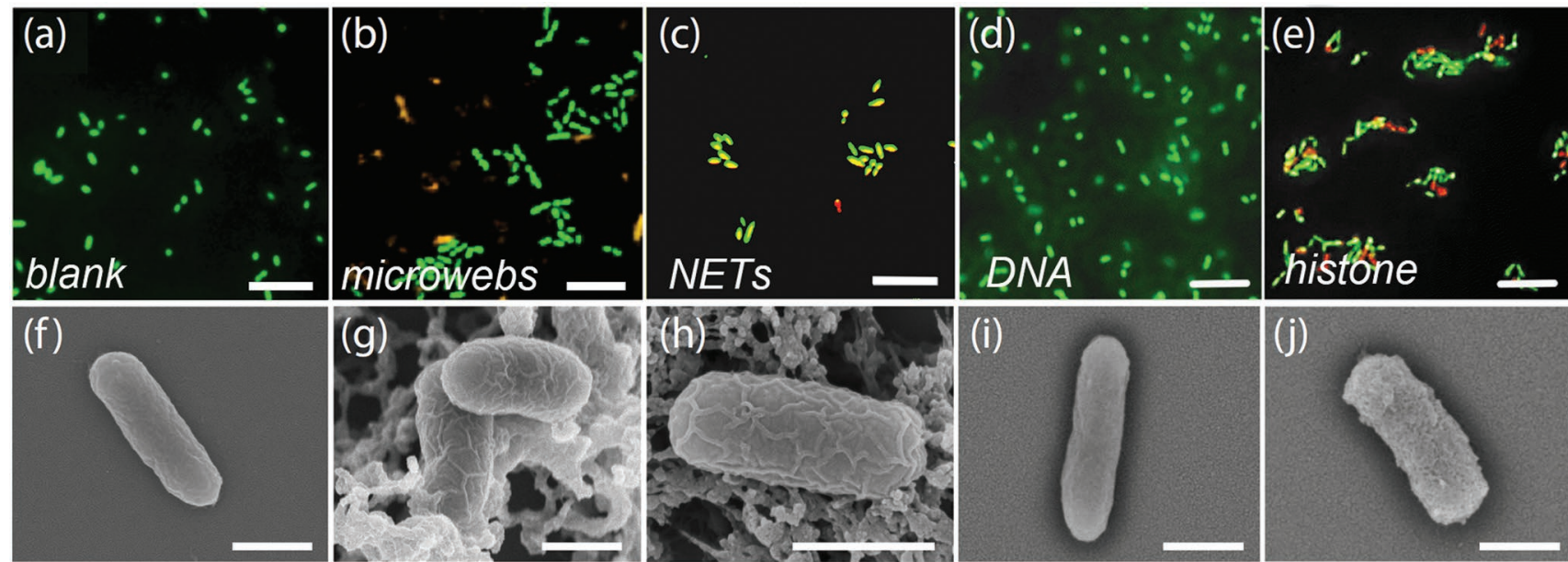

$(\mathrm{k})$

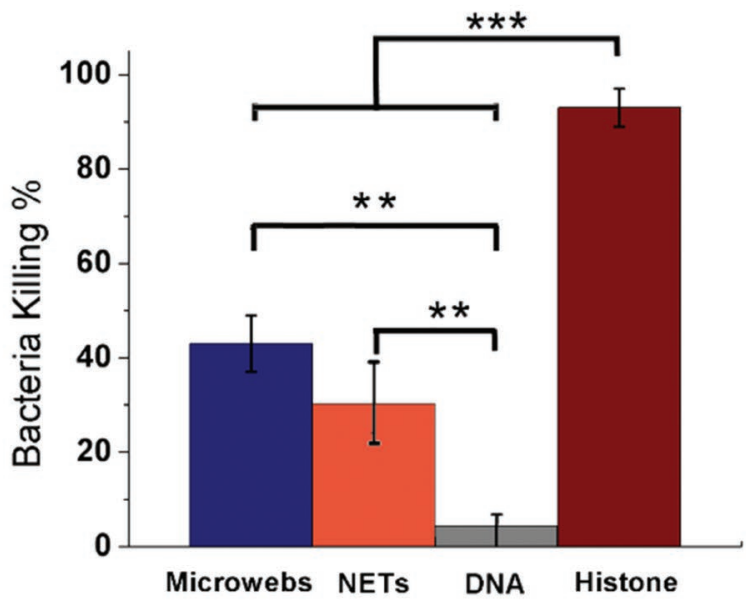

(I)

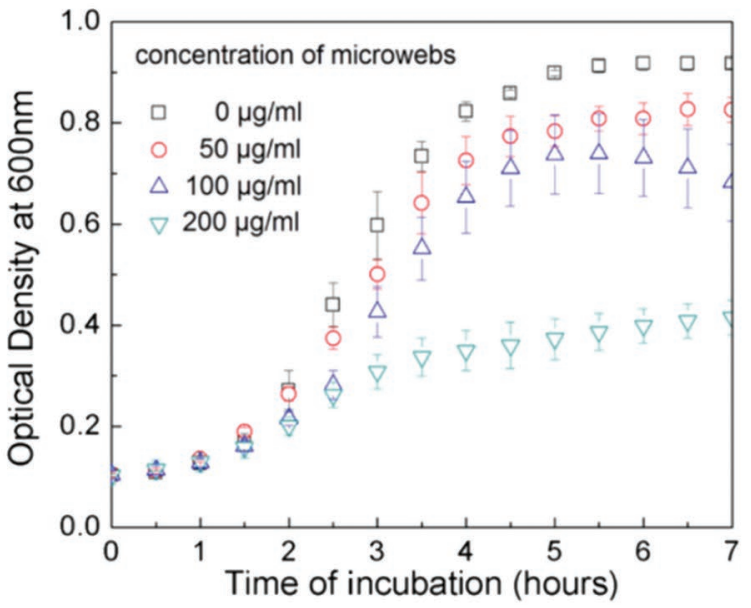

Figure 3. Viability assessment of $E$. coli cultured with microwebs. Fluorescence microscopy images of $E$. coli in a) tryptic soy broth, b) $100 \mu \mathrm{g} \mathrm{mL}^{-1}$ microwebs $\left(\omega_{\text {his }}=50 \%\right)$, c) $100 \mu \mathrm{g} \mathrm{mL} \mathrm{m}^{-1} \mathrm{NETs}$, d) $50 \mu \mathrm{g} \mathrm{mL}^{-1}$ DNA solution, and e) $50 \mu \mathrm{g} \mathrm{mL}^{-1}$ histone solution (live cells: green; dead cells: red). Scale bars $=10 \mu \mathrm{m}$. The corresponding SEM images of E. coli cells cultured in indicated solutions are shown in (f) to (j). Scale bars $=1 \mu \mathrm{m}$. $\mathrm{k}$ ) Microwebs reduce colony forming units of $E$. coli in HBSS. $10^{5} \mathrm{E}$. coli cells were incubated in $100 \mu \mathrm{L}$ microwebs $\left(50 \mu \mathrm{g} \mathrm{mL} \mathrm{m}^{-1} \mathrm{DNA}, \omega_{\text {his }}=50 \%\right), \mathrm{NETs}(\mathrm{contains}$ $50 \mu \mathrm{g} \mathrm{mL} \mathrm{L}^{-1}$ DNA, triggered by phorbol 12-myristate 13-acetate), $50 \mu \mathrm{g} \mathrm{mL}^{-1} \mathrm{DNA}$, and $50 \mu \mathrm{g} \mathrm{mL}^{-1}$ histone, respectively, for $1 \mathrm{~h}$ before transferred to agar plates. $* * P<0.01 ; * * * P<0.001$. Growth curves of $E$. coli in a mixture of $100 \mu \mathrm{L}$ microweb suspension and $100 \mu \mathrm{L}$ TSB plus $1 \%$ glucose. 
suggests loss of membrane integrity (Figure $3 \mathrm{~b}$ ). To determine which component in microwebs caused structural damage to E. coli cell wall, we separately cultured E. coli in the isolated DNA (Figure 3d,i) or histone solutions (Figure 3e,j). Within the range of physiologically relevant DNA concentrations (25-100 $\left.\mu \mathrm{g} \mathrm{mL} \mathrm{m}^{-1}\right)$, the viability of $E$. coli cells cultured in the DNA solution remained. In contrast, an increased cell death rate was observed after $E$. coli cells were cultured in a series of histone solutions with increasing protein concentration (25-100 $\mu \mathrm{g} \mathrm{mL} \mathrm{mL}^{-1}$ ). SEM observation of these dead cells showed damaged capsules with nanosized pores. Previous studies have shown that histone $\mathrm{H} 2 \mathrm{~B}$ penetrates through E. coli membrane, and histone $\mathrm{H} 3$ and $\mathrm{H} 4$ can destruct bacterial cell wall. ${ }^{[23]}$ To test if these membrane pores we observed are structural defects caused by dehydration of cells before SEM observation, we also used fluorescein isothiocyanate (FITC) to label histone and identify their bactericidal effect under CLSM. Our observation showed that FITC-histone alone can efficiently cause lysis of bacteria E. coli (Figure S3, Supporting Information). However, once complexed with DNA to form microwebs, the FITChistones no longer break the cell membrane. Instead, these FITC-histones were absorbed on the E. coli cell wall.

To further quantify the antimicrobial potency of microwebs, we cultured E. coli in suspensions with microwebs (in HBSS) before they were diluted and transferred to agar plates for colony forming unit (CFU) enumeration (Figure $3 \mathrm{k}$ ). The presence of microwebs $\left(100 \mu \mathrm{g} \mathrm{mL}^{-1}\right)$ reduces CFU counts of E. coli $\left(10^{6} \mathrm{~mL}^{-1}\right)$ by $41 \% \pm 8 \%$, in agreement with the reduced CFU counts in the NETs group (32\% $\pm 7 \%)$. By separately using DNA and histone as additives to culture medium, we confirmed that histone, rather than DNA, was the direct bactericidal component against $E$. coli. When $E$. coli were cultured in a nutrient-rich medium of $50 \mathrm{vol} \%$ TSB and 50 vol\% HBSS containing microwebs (Figure 31), we did not observe an immediate decline in the bacterial proliferation rate within the first $2 \mathrm{~h}$, perhaps due to the diffusion-limited penetration of histone through the E. coli cell wall. However, microwebs reduced the overall E. coli cell number in the stationary phase $(t=4-6 \mathrm{~h})$, which is attributed to the trapping and mild killing effects of the microwebs. After microwebs were dismantled by DNase $I$, the remaining structures no longer inhibit bacterial growth in the stationary phase (Figure S4, Supporting Information). Our observation suggests that the network of DNA nanofibers also contributes to the antimicrobial potency of the microwebs, in agreement with previous reports on DNase-induced loss of antimicrobial potency of NETs. ${ }^{[6,10,11]}$ The supernatant resulting from preparation of microwebs does not significantly change the growth curve of E. coli (Figure S4, Supporting Information), suggesting that free histone remaining in the supernatant is trivial. The antimicrobial mechanism of action of the microwebs, therefore, mainly relies on their direct contact with bacteria. Some of the entrapped E. coli cells exhibited phenotype changes, such as filamentous growth (Figure S5, Supporting Information). Filamentation is generally considered a protective strategy for bacteria to evade stressed conditions, such as antibiotic treatment and phagocytosis of macrophages. ${ }^{[24]}$ In view of the responses of E. coli to microwebs, we propose that microwebs are bacteriostatic networks with functions of trapping and moderate inhibition of E. coli proliferation.
As a structural and chemical analogue of NETs, microwebs can be used for convenient screening of antibiotics which may function cooperatively with physiologically-produced NETs. To test this hypothesis, we measured the tolerance of $E$. coli to different antibiotics with and without microwebs $\left(\omega_{\text {his }}=50 \%\right)$. Four clinically potent antibiotics for urinary tract infection, including amoxicillin, colistin sulfate, nitrofurantoin, and trimethoprim were tested. In HBSS, the antimicrobial potency of amoxicillin and colistin sulfate was significantly enhanced in the presence of microwebs $\left(100 \mu \mathrm{g} \mathrm{mL} \mathrm{m}^{-1}\right)$, as shown by quantitative culture in Figure 4a,b. This antibacterial enhancement was also identified by determining the minimum inhibitory concentration (MIC) by standard broth microdilution for each antibiotic with and without microwebs. Without addition of microwebs, the MICs of colistin sulfate and amoxicillin are 3 and $12 \mu \mathrm{g} \mathrm{mL} \mathrm{m}^{-1}$, respectively. With addition of microwebs, the MICs for colistin sulfate and amoxicillin were reduced to 0.75 and $6 \mu \mathrm{g} \mathrm{mL} \mathrm{m}^{-1}$, respectively. Similar antimicrobial enhancement was also observed when enumerating the CFU counts of colistin-resistant E. coli strain IHD86_4 (+mcr-1) in HBSS (Figure S6, Supporting Information). Colistin is a last resort antibiotic used against multidrug resistant $E$. coli that has a side effect of frequently causing acute kidney injury. ${ }^{[25]}$ Dosing at a level that is bactericidal while minimizing risk of kidney injury is an important clinical challenge. Our results suggest an interesting possibility that endogenous NETs may assist colistin in fighting bacteria in vivo, allowing for the use of lower doses than may seem necessary with conventional in vitro antibiotic susceptibility tests performed in the absence of NETs. Interestingly, colistin has been reported to sensitize human neutrophilinduced killing of resistant E. coli in vivo. ${ }^{[26]}$

From the growth curve of E. coli with colistin treatment, we observed that the slope of the exponential phase, which was not affected by colistin treatment alone (Figure 4c), decreased with increasing concentrations of colistin in the presence of microwebs (Figure 4d). As colistin sulfate disrupts the bacterial membrane, ${ }^{[27]}$ the decreased slope of the exponential growth phase may be explained by the enhanced permeability of the bacterial cell wall induced by histone. In comparison, the slopes of the exponential phase for the amoxicillin-treated E. coli were less affected by amoxicillin concentration, regardless of the presence of microwebs (Figure 4e,f). Amoxicillin can inhibit the synthesis of cell wall but does not disrupt the cell membrane; therefore, with the unchanged membrane permeability to histone, the slope of exponential phase does not change even with increased concentration of amoxicillin (Figure 4f) when it is below the MIC. Additionally, microwebs did not change the MIC for nitrofurantoin and trimethoprim (see Figure S7 in the Supporting Information), as nitrofurantoin targeted ribosomal proteins and trimethoprim inhibited DNA synthesis. ${ }^{[28]}$ Our results suggest that microwebs can collaboratively work with antibiotics that targets the bacterial cell envelope.

In summary, we synthesized NET-like microwebs through sonochemical complexation of DNA and histone. To the best of our knowledge, this is the first report demonstrating that manipulation on the morphology and composition of DNAhistone complex can achieve antimicrobial functions similar to endogenous NETs. By varying the ratio of DNA to histone, we correlated the bacteria trapping and antimicrobial properties 
(a)

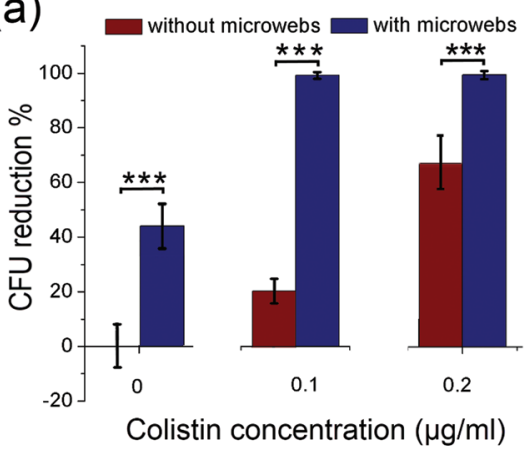

(d)

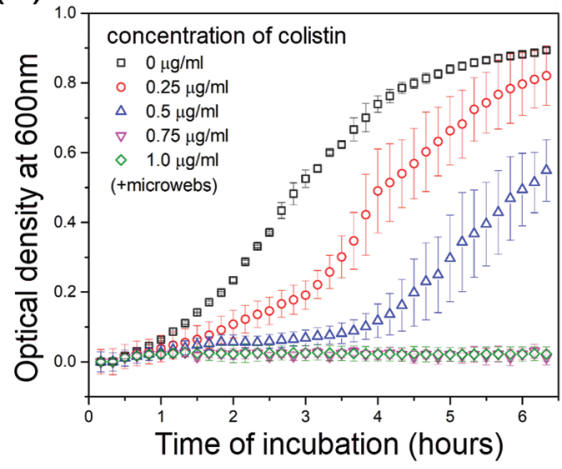

(b)

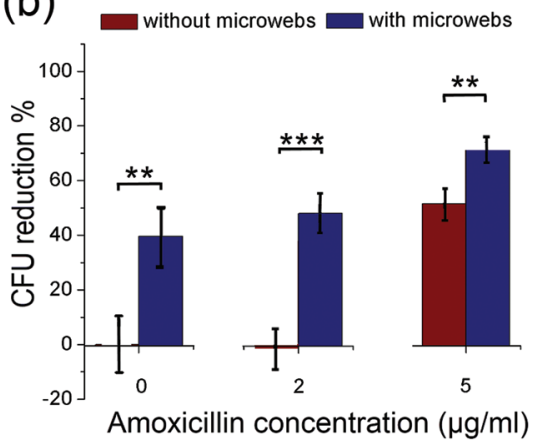

(e)

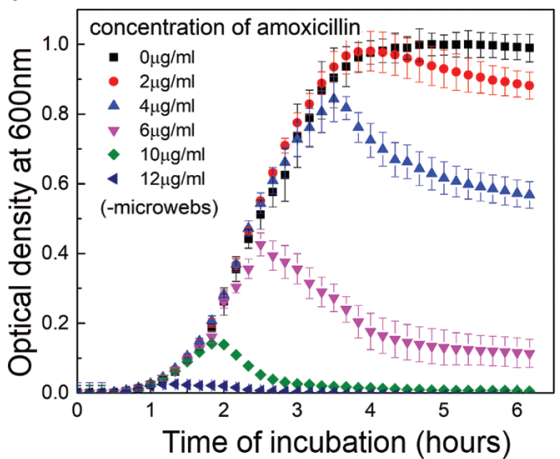

(c)

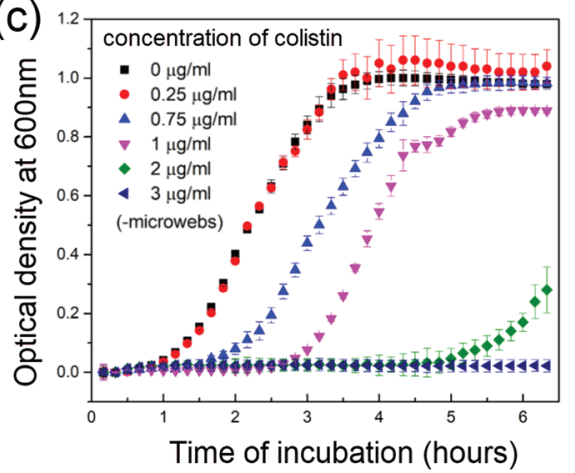

(f)

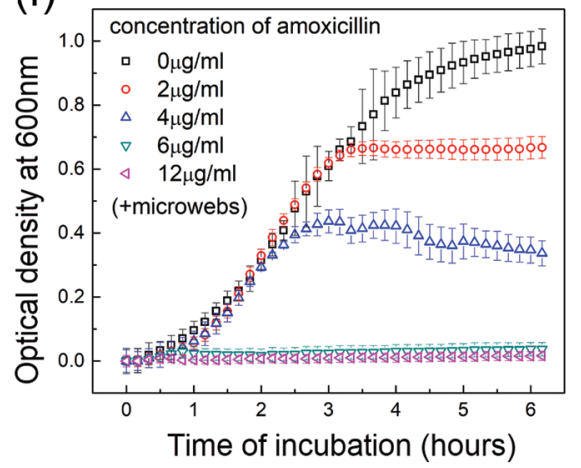

Figure 4. Microwebs can work cooperatively with antibiotics against E. coli. CFU counting of E. coli (inoculum $=10^{5}$ cells) after culture in a $100 \mu \mathrm{L}$ HBSS containing $100 \mu \mathrm{g} \mathrm{mL} \mathrm{m}^{-1}$ microwebs $\left(\omega_{\text {his }}=50 \%\right.$ ) plus antibiotics: a) colistin and b) amoxicillin for $1 \mathrm{~h}$ at $37^{\circ} \mathrm{C}$. Comparisons on the growth curves of E. coli (inoculum $=10^{6}$ cells) cultured in a mixture solution of $100 \mu \mathrm{L} \mathrm{TSB}, 100 \mu \mathrm{L}$ HBSS, microwebs, and antibiotics: c) with colistin, without microwebs; d) with colistin, with $50 \mu \mathrm{g} \mathrm{mL} \mathrm{L}^{-1}$ microwebs; e) with amoxicillin, without microwebs; and f) with amoxicillin, with $50 \mu \mathrm{g} \mathrm{mL} \mathrm{m}^{-1} \mathrm{microwebs}$. $* * P<0.01 ; * * * P<0.001$.

of the microwebs with regards to their DNA to histone ratio. This synthetic approach provides a flexible platform to quantitatively study the physiology role of different NET components. The compositionally minimalistic microwebs efficiently trap E. coli through electrostatic forces to an extent similar to NETs. DNase-mediated degradation experiments demonstrate that the network of DNA nanofibers also contribute to the inhibition of bacterial proliferation. E. coli exhibited filamentous growth, a well-known adaptive response, when exposed to both microwebs and NETs. Interestingly, microwebs work collaboratively with the last-resort antibiotic colistin and target bacterial cellenvelope, including colistin-resistant E. coli (IHD86_4 mcr-1). These results show that microwebs are useful for studying bacteria-NET interactions and for screening of antimicrobials that works collaboratively with physiologically-produced NETs. ${ }^{[29]}$ Since DNA-based NETs are also associated with pathology of some autoimmune diseases, ${ }^{[12]}$ further studies on microwebs should address their correlations with human disease or guide further efforts to design non-DNA based artificial NETs for clinical tests.

\section{Experimental Section}

Preparation of Microwebs: Microwebs was prepared by spontaneous polymerization of methylated lambda phage DNA in the presence of histone. Calf thymus histone (Sigma, H9250) and methylated lambda phage DNA (Sigma, D3779) were separately dissolved and diluted in
HBSS. The DNA (100-400 $\mu \mathrm{g} \mathrm{mL}^{-1}$ ) and histone concentration were measured from Nanodrop 2000c. To prepare microwebs, the DNA solution $\left(100 \mu \mathrm{L}, 100-400 \mu \mathrm{g} \mathrm{mL} \mathrm{L}^{-1}\right)$ was mixed with histone $(100 \mu \mathrm{L})$ solutions using an ultrasonic homogenizer (Qsonica Q125 sonicator, intensity set $20 \%$ ) for $15 \mathrm{~s}$. Depending on the weight fraction of histone in microwebs, the concentration of histone was varied from 33 to $400 \mu \mathrm{g} \mathrm{mL} \mathrm{m}^{-1}$. As a comparison, NETs isolated from neutrophils (see the experimental details in the Supporting Information) were dispersed into HBSS by sonication under the same conditions (intensity set $20 \%$, last for $15 \mathrm{~s})$.

Characterization: The zeta potentials of microwebs (DNA: $50 \mu \mathrm{g} \mathrm{mL}^{-1}$ ) were measured using a zetasizer (Malvern) at $37{ }^{\circ} \mathrm{C}$. Their size distribution was measured using Wyatt DynaPro NanoStar Dynamic Light Scattering. NETs formed from neutrophils were dispersed into HBSS by sonication for $15 \mathrm{~s}$ before DLS measurement. Morphology of microwebs (with and without E. coli) were imaged using scanning electron microscopy (Hitachi SU8230, $U_{\text {acc }}=1 \mathrm{kV}, I=15 \mathrm{~mA}$ ). The SEM samples were fixed by $4 \%$ paraformaldehyde, washed with deionized water, and sequentially dehydrated in $25,50,75,95$, and 100 vol\% ethanol. Subsequently, samples were immersed in hexamethyldisilane and vacuumed overnight. Dried samples were sputter-coated with gold nanoparticles (SPI-Module 60s, $18 \mathrm{~mA}$ ).

Degradation: Suspension of microwebs $(100 \mu \mathrm{L}$, preheated to $\left.37^{\circ} \mathrm{C}\right)$ was prestained with SYTOX green $\left(1 \times 10^{-6} \mathrm{M}\right)$ and mixed with DNase solutions (bovine pancreas DNase I, Sigma 11284932001, diluted in HBSS) at equal volumes. The final concentration of DNase was $1,10,100$, and $500 \mu \mathrm{g} \mathrm{mL} \mathrm{L}^{-1}$. Degradation of the microwebs was monitored in a Synergy Neo2 Multi-mode microplate reader (BioTek, $\mathrm{Ex} / \mathrm{Em}=488 / 523 \mathrm{~nm}$ ) at $37^{\circ} \mathrm{C}$ for $4 \mathrm{~h}$.

Bacterial Media and Growth Conditions: E. coli UTI89 was streaked on a tryptic soy agar (TSA, Sigma 22091) plate and incubated at $37^{\circ} \mathrm{C}$ 
overnight. One colony was scratched from TSA plate and suspended in $1 \mathrm{~mL}$ tryptic soy broth (Sigma 22092) with $1 \%$ glucose, until the optical density at $600 \mathrm{~nm}\left(\mathrm{OD}_{600}\right)$ of the cultures reached $0.3-0.6$. The E. coli suspension was diluted to $\mathrm{OD}_{600}=0.01$.

Bacteria-Trapping Assay: Suspension of microwebs $(100 \mu \mathrm{L}$, containing $50 \mu \mathrm{g} \mathrm{mL}^{-1}$ DNA) was pipetted into 96-well microplates and centrifuged $(4000 \mathrm{rpm}, 10 \mathrm{~min})$. E. coli culture $\left(100 \mu \mathrm{L}, \mathrm{OD}_{600}=0.01 \mathrm{in}\right.$ HBSS) prestained with SYTO 9 was added on top of the microwebs and centrifugated (4000 rpm, $10 \mathrm{~min}$ ). Motion of $E$. coli was continuously monitored for $1 \mathrm{~h}$ using fluorescence microscopy (Nikon Eclipse 80i). The percentage of trapped E. coli is expressed as the ratio of nonmotile E. coli to the total number of bacteria. After $1 \mathrm{~h}$ of incubation at $37^{\circ} \mathrm{C}$, the planktonic $E$. coli in the supernatant was collected, serial diluted by tenfold using HBSS, and transferred to agar plates. After overnight incubation, the E. coli colonies were numerated.

Cell Viability Assay: Suspension of E. coli cells $\left(100 \mu \mathrm{L}, \mathrm{OD}_{600}=0.01\right.$ in HBSS) was allocated into a 96-well microplate and centrifugated (4000 rpm, $10 \mathrm{~min}$ ). Afterward, suspension of microwebs (100 $\mu \mathrm{L}$ ) was slowly injected on top of cells and centrifuged (4000 rpm, $10 \mathrm{~min}$ ). After $1 \mathrm{~h}$ of incubation $\left(37^{\circ} \mathrm{C}\right)$, the microwebs on top of E. coli were removed by repeated pipette washing (HBSS) for 3-5 times. The E. coli cells attached to the microplate substrate were stained $\left(0.5\right.$ vol\% $3.34 \times 10^{-3} \mathrm{M}$ SYTO 9 and 0.5 vol\% $20 \times 10^{-3} \mathrm{M}$ propidium iodide, $15 \mathrm{~min}$, Thermofisher L7012), washed with deionized water, and imaged via fluorescence microscopy (Nikon Eclipse 80i, Nikon A1Rsi).

Bacteria Proliferation Assay: Proliferation of E. coli was measured from $\mathrm{OD}_{600}$ of the bacteria culture suspension using a plate reader (Biotek). $100 \mu \mathrm{L}$ TSB containing $10^{6} \mathrm{E}$. coli cells were mixed with $100 \mu \mathrm{L}$ microwebs (in HBSS, $w_{\text {his }}=50 \%$ ) at different concentrations of $0,25,50$, and $100 \mu \mathrm{g} \mathrm{mL} L^{-1}$. E. coli were cultured at $37^{\circ} \mathrm{C}$ for $7 \mathrm{~h}$ and their corresponding $O D_{600}$ values were measured $\left(\mathrm{OD}_{600}\right.$ of microweb suspension without E. coli was subtracted as background). Three independent bacteria colonies were used. Data are presented as mean values \pm S.D.

Quantitative Culture: $10^{5} \mathrm{E}$. coli cells (in $10 \mu \mathrm{L}$ HBSS) were mixed with suspension of microwebs $\left(100 \mu \mathrm{L}, 100 \mu \mathrm{g} \mathrm{mL}^{-1}\right.$ in HBSS) and incubated for $1 \mathrm{~h}\left(37^{\circ} \mathrm{C}\right)$. Next, $10 \mu \mathrm{L}$ mixture was extracted from each sample and diluted with HBSS at a volumetric ratio of 1:1000. Subsequently, $10 \mu \mathrm{L}$ of the diluted solution samples was spotted onto the agar plate; this liquid transfer was repeated 6 times for each sample. The spotted agar plate was incubated at $37^{\circ} \mathrm{C}$ for $12 \mathrm{~h}$. The numbers of CFUs were then enumerated. Four different E. coli colonies were tested for CFU enumeration, and unpaired Student's $t$-test was employed to quantify the statistical significance using $P$-values.

Antibiotic Tests: Four antibiotics were separately dissolved in deionized water as stock solutions (colistin, Sigma, PHR1605 $20 \mu \mathrm{g} \mathrm{mL} \mathrm{L}^{-1}$;

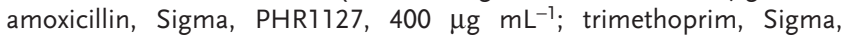
PHR1056 $200 \mu \mathrm{g} \mathrm{mL}^{-1}$; nitrofurantoin, Sigma, PHR1191, $1 \mathrm{mg} \mathrm{mL}^{-1}$ ). These antibiotics were diluted in either suspension of microwebs or HBSS to desired concentrations. For quantitative culture, $10^{5}$ cells were suspended in a mixture of $100 \mu \mathrm{L}$ HBSS (with and without $100 \mu \mathrm{g} \mathrm{mL} \mathrm{L}^{-1}$ microwebs) and $100 \mu \mathrm{L}$ antibiotic solution. For growth curves, $10^{6}$ cells were seeded in a mixture of $100 \mu \mathrm{L} \mathrm{TSB}, 100 \mu \mathrm{l} \mathrm{HBSS}$ (with and without $100 \mu \mathrm{g} \mathrm{mL}-1$ microwebs microwebs) and antibiotics. Quantitative culture and growth curves were performed following the same protocols as above. The MIC was determined by standard broth microdilution. $10^{6}$ cells $\mathrm{mL}^{-1}$ were inoculated into increasing concentrations of antibiotic \pm microwebs. After 16 -h incubation at $37^{\circ} \mathrm{C}$, the MIC was identified as the lowest concentration with no visible bacterial growth.

\section{Supporting Information}

Supporting Information is available from the Wiley Online Library or from the author.

\section{Acknowledgements}

This research project was funded by the National Institutes of Health $(\mathrm{NIH}$ NIAID U19 Al116482, R01 Al141883, and K08 Al128006; NIGMS R01
GM123517; NHLBI R01 HL134846; and U01 CA210152), the Veterans Administration (Merit award BX-002788), and a Burroughs Wellcome Fund Investigator in the Pathogenesis of Infectious Disease award.

\section{Conflict of Interest}

The authors declare no conflict of interest.

\section{Keywords}

antibiotic resistance, bacteria E. coli, biomimetic materials, DNA nanofiber networks, neutrophil extracellular traps

Received: November 17, 2018 Revised: January 16, 2019 Published online: January 30, 2019

[1] T. A. Blackledge, N. Scharff, J. A. Coddington, T. Szüts, J. W. Wenzel, C. Y. Hayashi, I. Agnarsson, Proc. Natl. Acad. Sci. USA 2009, 106, 5229.

[2] a) D. K. V. Kumar, S. H. Choi, K. J. Washicosky, W. A. Eimer, S. Tucker, J. Ghofrani, A. Lefkowitz, G. McColl, L. E. Goldstein, R. E. Tanzi, R. D. Moir, Sci. Transl. Med. 2016, 8, 340ra72; b) U. Shimanovich, I. Efimov, T. O. Mason, P. Flagmeier, A. K. Buell, A. Gedanken, S. Linse, K. S. Åkerfeldt, C. M. Dobson, D. A. Weitz, T. P. Knowles, ACS Nano 2015, 9, 43.

[3] L. Drago, M. Bortolin, C. Vassena, S. Taschieri, M. Del Fabbro, BMC Microbiol. 2013, 13, 47

[4] V. Brinkmann, A. Zychlinsky, Nat. Rev. Microbiol. 2007, 5, 577.

[5] V. Papayannopoulos, K. D. Metzler, A. Hakkim, A. Zychlinsky, J. Cell Biol. 2010, 191, 677.

[6] a) V. Brinkmann, U. Reichard, C. Goosmann, B. Fauler, Y. Uhlemann, D. S. Weiss, Y. Weinrauch, A. Zychlinsky, Science 2004, 303, 1532; b) R. L. Young, K. C. Malcolm, J. E. Kret, S. M. Caceres, K. R. Poch, D. P. Nichols, J. L. Taylor-Cousar, M. T. Saavedra, S. H. Randell, M. L. Vasil, J. L. Burns, PLoS One 2011, 6, e23637.

[7] C. F. Urban, U. Reichard, V. Brinkmann, A. Zychlinsky, Cell. Microbiol. 2006, 8, 668 .

[8] C. N. Jenne, C. H. Wong, F. J. Zemp, B. McDonald, M. M. Rahman, P. A. Forsyth, G. McFadden, P. Kubes, Cell Host Microbe 2013, 13, 169.

[9] A. B. Guimarães-Costa, M. T. Nascimento, G. S. Froment, R. P. Soares, F. N. Morgado, F. Conceição-Silva, E. M. Saraiva, Proc. Natl. Acad. Sci. USA 2009,106, 6748.

[10] a) F. Wartha, K. Beiter, B. Albiger, J. Fernebro, A. Zychlinsky, S. Normark, B. Henriques-Normark, Cell. Microbiol. 2007, 9, 1162; b) F. Ma, L. Yi, N. Yu, G. Wang, Z. Ma, H. Lin, H. Fan, Front. Cell. Infect. Microbiol. 2017, 7, 86.

[11] a) R. Menegazzi, E. Decleva, P. Dri, Blood 2012, 119, 1214; b) V. Thammavongsa, D. M. Missiakas, O. Schneewind, Science 2013, 342, 863

[12] a) V. Marcos, Z. Zhou, A. Ö. Yildirim, A. Bohla, A. Hector, L. Vitkov, E. M. Wiedenbauer, W. D. Krautgartner, W. Stoiber, B. H. Belohradsky, N. Rieber, Nat. Med. 2010, 16, 1018; b) V. Papayannopoulos, Nat. Rev. Immunol. 2018, 18, 134.

[13] C. F. Urban, D. Ermert, M. Schmid, U. Abu-Abed, C. Goosmann, W. Nacken, V. Brinkmann, P. R. Jungblut, A. Zychlinsky, PLoS Pathog. 2009, 5, e1000639.

[14] C. Mottola, D. Romeo, J. Cell Biol. 1982, 93, 129. 
[15] S. R. Clark, A. C. Ma, S. A. Tavener, B. McDonald, Z. Goodarzi, M. M. Kelly, K. D. Patel, S. Chakrabarti, E. McAvoy, G. D. Sinclair, E. M. Keys, Nat. Med. 2007, 13, 463.

[16] B. G. Yipp, B. Petri, D. Salina, C. N. Jenne, B. N. Scott, L. D. Zbytnuik, K. Pittman, M. Asaduzzaman, K. Wu, H. C. Meijndert, S. E. Malawista, Nat. Med. 2012, 18, 1386.

[17] J. P. Frampton, M. Tsuei, J. B. White, A. T. Abraham, S. Takayama. Biotechnol. J. 2015, 10, 121

[18] a) Y. Liu, M. Guthold, M. J. Snyder, H. Lu, Colloids Surf., B 2015, 134, 17 b) L. A. Lanier, H. Bermudez, Macromol. Rapid Commun.39, 1800342; c) M. Roushan, M. Jorfi, A. Mishra, K. H. K. Wong, J. Jorgensen, E. Ell, J. F. Markmann, J. Lee, D. Irimia. Adv. Biosyst.2, 1800040.

[19] a) T. H. Ng, M.-H. Wu, S.-H. Chang, T. Aoki, H.-C. Wang, Dev. Comp. Immunol. 2015, 48, 229; b) R. J. Meinersmann, S. R. Ladely, J. R. Plumblee, M. C. Hall, S. A. Simpson, L. L. Ballard, B. E. Scheffler, L. L. Genzlinger, K. L. Cook, Genome Announce. 2016, 4, e00898.

[20] a) R. H. Pires, S. B. Felix, M. Delcea, Nanoscale 2016. 8, 14193; b) R. Manzenreiter, F. Kienberger, V. Marcos, K. Schilcher W. D. Krautgartner, A. Obermayer, M. Huml, W. Stoiber, A. Hector, M. Griese, M. Hannig, J. Cystic Fibrosis 2012, 11, 84.

[21] V. Papayannopoulos, D. Staab, A. Zychlinsky, PLoS One 2011, 6, e28526.
[22] a) M. Floyd, M. Winn, C. Cullen, P. Sil, B. Chassaing, D. Yoo, A. T. Gewirtz, J. B. Goldberg, L. L. McCarter, B. Rada. PLoS Pathog. 2016, 12, e1005987. b) V. Brinkmann, A. Zychlinsky, J. Cell Biol. 2012, 198, 773.

[23] a) J. G. Hirsch, J. Exp. Med. 1958, 108, 925. b) C. Tagai, S. Morita, T. Shiraishi, K. Miyaji, S. Iwamuro, Peptides 2011, 32, 2003

[24] a) Y. Yu, K. Kwon, T. Tsitrin, S. Bekele, P. Sikorski, K. E. Nelson, R. Pieper, PLoS Pathog. 2017, 13, e1006151; b) S. S. Justice, D. A. Hunstad, P. C. Seed, S. J. Hultgren, Proc. Natl. Acad. Sci. USA 2006, 103, 19884.

[25] L. Dalfino, F. Puntillo, M. J. M. Ondok, A. Mosca, R. Monno, S. Coppolecchia, M. L. Spada, F. Bruno, N. Brienza. Clin. Infect. Dis. 2015, 61, 1771.

[26] F. Rose, K. U. Heuer, U. Sibelius, S. Hombach-Klonisch, L. Kiss, W. Seeger, F. Grimminger. J. Infect. Dis. 2000, 182, 191.

[27] J. Li, R. L. Nation, R. W. Milne, J. D. Turnidge, K. Coulthard, Int. J. Antimicrob. Agents 2005, 25, 11.

[28] M. Koike, K. lida, MatsuoT. J. Bacteriol. 1969, 97, 448.

[29] M. W. Munks, A. S. McKee, M. K. MacLeod, R. L. Powell, J. L. Degen, N. A. Reisdorph, J. W. Kappler, P. Marrack, Blood 2010, 116, 5191. 